\title{
Pneumoencéfalo y pneumorraquis traumático: reporte de caso y revisión de la literatura
}

Loraine Quintana-Pájaro ${ }^{1,2}$, Abigail Castilla-Martínez ${ }^{1,2}$, Willem Guillermo Calderón-Miranda ${ }^{4}$, Yancarlos Ramos-Villegas ${ }^{1,2}$, Daniela Gómez-Herazo ${ }^{1,2}$, Maximiliano Paez-Nova ${ }^{5}$, Luis Rafael Moscote-Salazar ${ }^{2,3}$

1 Estudiante investigador. Facultad de Medicina, Universidad de Cartagena, Cartagena de Indias, Colombia.

2 Centro de Investigaciones Biomédicas (CIB), Línea Cartagena Neurotrauma Research Group, Universidad de Cartagena, Cartagena, Colombia.

3 Médico. Especialista en Neurocirugía. Faculta de Medicina, Universidad de Cartagena. Cartagena de Indias, Bolívar.

4 Médico Residente de Radiología. Universidad Nacional Autónoma de México (UNAM), Ciudad de México, México.

5 Médico. Especialista en Neurocirugía. Instituto de Neurocirugía Asenjo. Clínica Santa María. Santiago, Chile.

Rev. Chil. Neurocirugía 45: 80-86, 2019

\section{Resumen}

El pneumoencéfalo, o presencia de aire en la cavidad intracraneana, se ha asociado principalmente a lesiones traumáticas y se presenta como una complicación que, aunque poco frecuente, muestra altos índices de mortalidad. Ésta puede comportarse como una lesión ocupante de espacio y aumentar la presión intracraneana. Así, aunque la sintomatología no es específica, es necesario sospechar de esta entidad para realizar el diagnóstico y tratamiento oportunos. Se presenta el caso de un varón de 23 años con lesión cortopunzante en cuello, brazo y región lumbar, quién desarrolla un cuadro de cefalea temporal que finalmente se irradia a región cervical y que empeora en bipedestación. Se realizan estudios imagenológicos identificándose aire en cavidad intracraneal e intrarraquídea. Se realiza manejo conservador con evolución satisfactoria.

Palabras clave: Pneumoencéfalo, pneumorraquis, cefalea, presión intracraneana.

\begin{abstract}
Pneumocephalus, or the presence of air in the intracranial cavity, has been associated mainly with traumatic injuries and is a complication that, although rare, shows high mortality rates. The pneumorraquis is an entity that can be found incidentally and is mainly associated with traumatic injuries. Pneumocephalus can behave as a space-occupying lesion and increase intracranial pressure. Thus, although the symptomatology is not specific, it is necessary to suspect this entity to make the diagnosis and treatment timely. We present the case of a 23-year-old man with a sharp injury in the neck, arm and lumbar region, who develops a temporal headache that finally radiates to the cervical region and worsens in standing.
\end{abstract}

Key words: Pneumocephalus, pneumorraquis, headache, intracranial pressure.

\section{Introducción}

Nos referimos a pneumoencéfalo (aerocele o neumatocele) como la entrada de aire a la cavidad intracraneana ${ }^{1-3}$. El primer caso de aire en la cavidad intracraneal fue descrito en 1866 por Lecat, sin embargo, no fue hasta 1914 que Wolf publicó esta condición bajo la denominación de " pneumoencéfalo"1. La principal causa de esta complicación es el trauma intracraneal, generalmente fractura de base de cráneo, y lesiones en médula espinal, ya sean por accidentes traumáticos o iatrogenia. Es muy poco frecuente la presencia de pneumoencéfalo después de un procedimiento quirúrgico, sin embargo, durante inter- venciones espinales hay alta probabilidad de lesión de duramadre y fuga de líquido cefalorraquídeo (LCR) que da pie a la aparición de $p$ pneumoencéfalo, el cual es una de sus complicaciones más severas ya que puede conllevar a hemorragia intracraneal y posterior muerte ${ }^{2,3}$. El pneumoencéfalo también se ha asociado a procesos infecciosos, neo- 
plasias, uso de óxido nitroso durante la anestesia, hiperventilación, barotrauma, hidrocefalia y uso de anestesia epidural. Este acumulo de aire, que puede encontrarse en cualquier compartimiento intracraneal (epidural, subdural, subaracnoideo, intraparenquimatoso, intraventricular), puede comportarse como una lesión ocupante de espacio y aumentar así la presión intracraneana, los pacientes suelen cursar con síntomas bastante inespecíficos tales como cefalea, náuseas, vómitos, convulsiones y una severa depresión neurológica ${ }^{1,3}$. En el caso del pneumorraquis, este fue descrito por primera vez en la década de los setenta por Gordon et al, aunque Newbold et al fueron los que acuñaron el término ${ }^{4}$. A continuación, se presenta un caso de pneumoencéfalo y pneumorraquis asociado a una lesión cortopunzante en columna vertebral, con posterior revisión de la literatura de los casos publicados de pneumoencéfalo y pneumorraquis.

\section{Descripción del caso}

Paciente masculino de 23 años, sin antecedentes personales importantes. Ingresa al servicio de urgencias por herida cortopunzante en cuello, nariz, brazo y región lumbar. Posteriormente, inicia un cuadro de cefalea en región temporal, no irradiado y con puntuación de 5/10 en la escala análoga del dolor. Al día siguiente el paciente presenta temperatura cuantificada en $38^{\circ}$ grados y con cefalea con puntuación de 10/10 e irradiación a región cervical que empeora en bipedestación, motivo por el cual decide consultar al servicio de urgencias. En la exploración física se encuentra una TA: 116/71 mmHg, FC:74 latidos/minutos, FR:23 respiraciones/minutos, T:36 ${ }^{\circ}$. El paciente está consciente, orientado en tiempo, espacio y persona, con fascie algica. Como datos positivos se halló: Dolor a la palpación profunda en fosa ilíaca izquierda y región suprapúbica y herida en región lumbar con salida de líquido cefalorraquídeo. Sin alguna alteración en el examen neurológico. Se solicita una TAC simple de cráneo y de columna, que evidencia hallazgos compatibles con pneumoencéfalo y pneumorraquis. (Figuras $1 \mathrm{~A}$, y B, $2 \mathrm{~A}$, $\mathrm{B}$ y $\mathrm{C})$. Se considera que paciente presenta fistula de líquido cefalorraquídeo activa. Se decide manejo conservador con antibioticoterapia empírica de am-

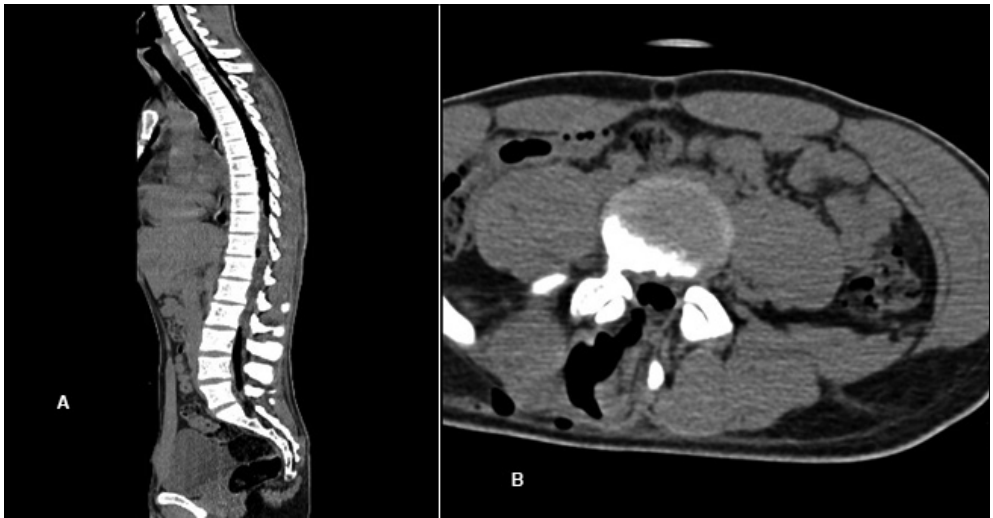

Figura 1. A y B. TAC de columna dorsolumbar (Corte Sagital) que evidencia aire en cavidad intraraquidea en segmentos dorsal y lumbar; (Corte axial) que muestra aire en trayecto de lesión desde tejido subcutaneo hasta cavida intraraquidea.

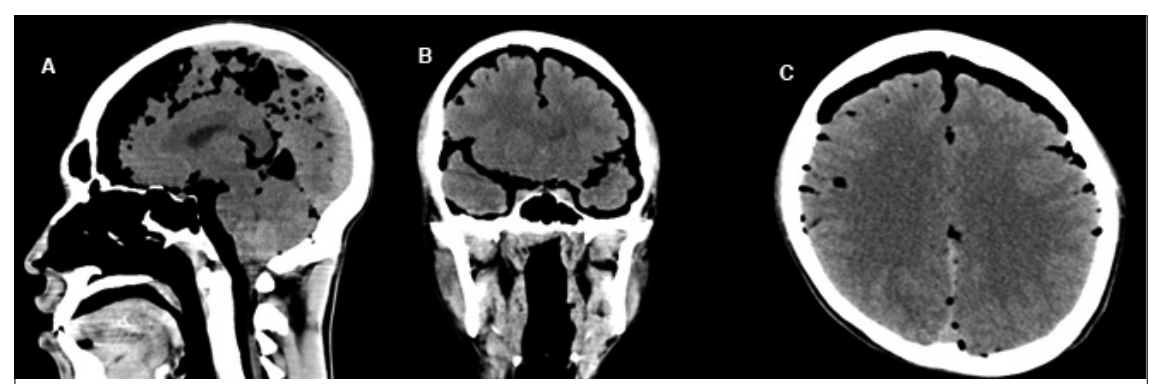

Figura 2. A ,B y C. TAC de cráneo simple (Corte Sagital, coronal y axial) que evidencia aire en cavidad intracraneana.

plio espectro (ceftriaxona $2 \mathrm{~g}$ IV c/12 horas) por 10 días. Paciente evoluciona satisfactoriamente con punción lumbar negativa para neuro infección. Se da alta medica a los 14 días y en controles imagenológicos el pneumoencéfalo resolvió espontáneamente.

\section{Discusión}

\section{Definición y epidemiología}

El pneumoencéfalo y el pneumorraquis hacen referencia a la presencia de aire en la cavidad intracraneana y médula espinal, respectivamente ${ }^{5}$. Desde el punto epidemiológico, el pneumorraquis constituye un hallazgo incidental en los exámenes imagenológicos y en la mayoría de los casos se relaciona con injuria traumática ${ }^{4}$. Por otro lado, el pneumoencéfalo se presenta como una complicación de lesiones craneales entre el $4-10 \%{ }^{6}$, aunque puede aparecer de forma espontánea en el $0,6 \%$ de los casos $^{7}$. En los pacientes con pneumorrhachis post-traumática se exhibe en un $78 \%$ aproximadamente ${ }^{2}$.

\section{Etiología y clasificación}

El pneumoencéfalo se puede clasificar en dos grandes categorías: traumático y no traumático ${ }^{7,8}$. La principal causa de pneumoencéfalo es el traumatismo, por otro lado, se encuentran los tumores, infecciones (meningitis y abscesos), fístula de LCR, procedimientos diagnósticos y terapéuticos $(3,6)$. Suele aparecer después de la fractura del base del cráneo, hueso temporal o seno paranasal $^{5}$. A nivel espinal, se destaca el traumatismo espinal, tumores, infección $n^{1,3}$, procedimientos espinales y la lesión dural durante la operación espinal ${ }^{3,9}$. Estas últimas como consecuencias de la inyección de aire mientras se identifica el espacio epidural ${ }^{9}$. Otras causas raras de pneumoencéfalo incluyen la ruptura traumática o iatrogénica de la duramadre espinal ${ }^{3}$. El barotrauma secundario a rápidos cambios de la presión del aire puede cambiar casos subclínicos a sintomáticos de pneumoencéfalo a tensión que demandan manejo y evacuación urgente ${ }^{1}$. El pneumoencéfalo espontáneo también se ha observado después de la intervención anestésica ${ }^{5}$. El aire puede 
localizarse en espacios subdurales, subaracnoideos, epidurales, intraventriculares e intraparenquimatosos ${ }^{3}$. Según el tiempo de evolución la acumulación de aire intracraneal puede ser aguda (< $72 \mathrm{~h}$ ) o retardada $(\geq 72 \mathrm{~h})^{6}$.

\section{Fisiopatología}

El aire llega al encéfalo a través de una irrupción de la integridad de la envoltura meníngea7. Se han propuesto 4 posibles mecanismos fisiopatológicos:

1) Mecanismo de botella invertida: la salida incesante de LCR induce presión intracraneal negativa dentro del espacio subaracnoideo, por lo que se sustituye al LCR perdido por aire, con el fin de equilibrar la diferencia de presión ${ }^{1,3,5,6,8,10}$.

2) Mecanismo de la válvula de bola: el aire ingresa a la cavidad intracraneal por medio de un defecto cuando se excede la presión intracraneal por la presión extracraneal (maniobras de estornudo, tos y valsalva) $)^{1,3,5,6,8,10,11}$. Explicando el empeoramiento del pneumoencéfalo mediante ventilación no invasiva ${ }^{12}$.

3) Anestesia con óxido nitroso $\left(\mathrm{N}_{2} \mathrm{O}\right)$ : el $\mathrm{N}_{2} \mathrm{O}$ se difunde fácilmente a una cavidad llena de aire, aumentando el volumen y presión del pneumoencéfalo ${ }^{3}$.

4) Origen Bacteriano: la presencia de bacterias formadoras de gas favorece la aparición de pneumoencéfalo ${ }^{3}$.

\section{Manifestaciones clínicas}

El cuadro clínico del neumoencéfalo es inespecífico, y los síntomas que refieren los pacientes tienden a ser confusos y con frecuencia desestimables posterior a la anestesia general en cirugías espinales. Se pueden encontrar los pacientes con cefalea, náuseas, vómitos, mareos, letargo, alteración de la conciencia que puede evolucionar hasta coma, y meningismos $3,5,8,13,14$. No obstante, la mayor parte de casos reportados son asintomáticos y de evolución benigna, remediándose a las 3 semanas aproximadamente ${ }^{7}$ Grzegorz P. Kozikowski et al. Describieron un pneumoencéfalo asociado a punción lumbar cuya resolución fue a los cuatro días espontáneamente ${ }^{9}$. Por otra parte, el pneumoencéfalo a tensión incluye no solo cefalea, también convulsiones generalizadas, delirio, anomalías reflejas, alteración de conciencia, pupilares y el síndrome del lóbulo frontal; y de localizarse en fosa posterior puede cursar con alteraciones respiratorias y cardiacas que conduzcan a paro cardiorrespiratorio ${ }^{6}$. En el caso de los pacientes que solo desarrollan pneumorraquis, estos suelen ser asintomáticos en la mayoría de los casos, aunque algunos pueden presentar un cuadro neurológico caracterizado por compromiso del nivel de conciencia o signos similares a una meningitis ${ }^{4}$.

\section{Imagenología}

El diagnóstico del trastorno es radiológico, se hace por medio de imágenes de radiografía simple, tomografía computarizada y resonancia magnética, que dependen directamente de la cantidad de aire en la cavidad craneana o los espacios espinales, bien se pneumoencéfalo o pneumorraquis respectivamente ${ }^{15}$. La radiografía se usó por primera vez para diagnóstico de pneumoencéfalo en el año 1913 por Luckett ${ }^{7,8}$. En cambio, la tomografía se posicionó luego por encima de la resonancia como el estudio con más sensibilidad y especificidad para identificar hasta $0,5 \mathrm{cc}$ de aire en la cavidad ${ }^{3,5}$ sumado a que permite realizar seguimiento de su expansión o progreso $^{13}$

En tomografía, el hallazgo es principalmente aire en los diferentes espacios intracraneales cuya característica es la hipodensidad aumentada o en espacios en donde normalmente no se debe encontrar, pueden verse como burbujas de aire diseminadas en caso de neumoencéfalo a tensión que de romper la aracnoides puede ingresar a el espacio subaracnoideo. No obstante, la tomografía no logra diferenciar el pneumorraquis intradural del extradural, lo que hace necesario el uso de resonancia magnética $^{8,15}$. En el caso de pneumorraquis, se ha propuesto clasificarlo en tres grados de acuerdo a las imágenes mostradas por tomografía y el tamaño mostrado en la Tabla $1^{15}$.

\section{Tratamiento}

El manejo de pneumorraquis, frecuen-

Tabla 1.

Clasificación para Pneumorraquis

Postraumático (PTSD)

\begin{tabular}{|l|l|}
\hline Grado & Características \\
\hline I & $\begin{array}{l}\text { Pneumorraquis periférico } \\
\text { que ocupa menos del } 30 \%\end{array}$ \\
\hline II & Ocupa menos del $60 \%$ \\
\hline III & Ocupa más del $60 \%$ \\
\hline
\end{tabular}

temente está asociado a las lesiones asociadas, y la presencia de aire permite la identificación de la enfermedad subyacente ${ }^{15}$. El tratamiento del pneumoencéfalo no está definido, y el aire intracraneal se absorbe espontáneamente en $85 \%$ de los $\operatorname{casos}^{5}$. El manejo inicial es conservador basado en descanso o reposo en cama, oxigenación al $100 \%$ ya que permite la absorción del nitrógeno rápidamente, hidratación, analgesia, sedación, antieméticos y antibióticos si existe la certeza de meningismos, habitualmente mejora o soluciona el cuadro en unas 3 semanas $^{1,5,7}$. Se deben evitar realizar actividades que predispongan a un aumento de la presión intracraneal como sonarse la nariz o la maniobra de Valsalva ${ }^{6,7}$. Se ha descrito la posición de trendelemburg como un posible mecanismo de prevención de pneumoencéfalo, puesto que se mantiene la cabeza más baja que el lugar de entrada de aire ${ }^{2,3}$. La administración de oxígeno al 100\%, permite que el pneumoencéfalo que se encuentra cargado con aire ambiente con un contenido de $78 \%$ nitrógeno, se concentre en el torrente sanguíneo y difunda desde la cavidad intracraneal hacia la intravascular, disminuyendo el volumen de aire en el encéfalo progresivamente $^{8,13}$

El manejo quirúrgico se convierte en la segunda opción terapéutica, cuando la terapia conservadora no tiene resultado, asociado con casos de pneumoencéfalo que actúan como lesiones ocupantes de espacio, pneumoencéfalo a tensión, pneumoencéfalo recurrente o aumento de la presión intracraneal ${ }^{6}$. El manejo en estas situaciones es de emergencia, y es esencial la descompresión por craneotomía con el objetivo de prevenir herniación de las estructuras encefálicas y la muerte 7,8 .

Siempre y cuando el defecto sea pequeño, la terapia conservadora en la mayoría de los casos ha demostrado ser eficaz sin necesidad de procedimientos invasivos de resolución, al contrario de los más grandes ocupantes de espacio, cuyo procedimiento indicado es quirúrgico, debido a que el manejo inicial conservador no es muy eficaz al resolverlos. Dentro de las medidas quirúrgicas utilizadas se encuentran el drenaje subdural. Sin embargo, el drenaje lumbar puede complicar la clínica del pneumoencéfalo al conducir a más presión intracraneal negativa y extraer aire intracraneal ${ }^{10}$ 
Tabla 2.

Reportes de caso de pneumoencéfalo más pneumorraquis

\begin{tabular}{|c|c|c|c|c|c|c|c|}
\hline Autores & Año & Edad & Género & Mecanismo & Síntomas & $\begin{array}{l}\text { Hallazgos image- } \\
\text { nológicos }\end{array}$ & Referencia \\
\hline Schömig et al & 2016 & 67 & $M$ & $\begin{array}{l}\text { Cuerpo extraño } \\
\text { (prótesis dental) en } \\
\text { unión ileocecal. Con } \\
\text { posible fistula ente- } \\
\text { rodural }\end{array}$ & $\begin{array}{l}\text { Dolor de espalda, } \\
\text { fiebre }\left(38.7^{\circ} \mathrm{C}\right), \\
\text { desorientación en } \\
\text { tiempo, espacio y } \\
\text { persona }\end{array}$ & $\begin{array}{l}\text { Pneumoencéfalo } \\
\text { subaracnoideo difu- } \\
\text { so y pneumorraquis } \\
\text { en L5-S1 }\end{array}$ & (16) \\
\hline $\begin{array}{l}\text { Hsieh X-X, } \\
\text { et al }\end{array}$ & 2015 & 72 & $F$ & $\begin{array}{l}\text { Secundario a anes- } \\
\text { tesia epidural }\end{array}$ & $\begin{array}{l}\text { Alteración de la } \\
\text { conciencia con } \\
\text { posterior crisis } \\
\text { convulsivas }\end{array}$ & $\begin{array}{l}\text { Pneumoencéfalo en } \\
\text { fosa craneal bila- } \\
\text { teral anterior, me- } \\
\text { dia y posterior y el } \\
\text { seno cavernoso más } \\
\text { pneumorraquis }\end{array}$ & (17) \\
\hline Kara $\mathrm{H}$ et al & 2015 & $\begin{array}{l}31 \\
40\end{array}$ & $\begin{array}{l}M \\
M\end{array}$ & $\begin{array}{l}\text {-Herida punzante } \\
\text { en c5-c6 } \\
\text {-Herida punzante } \\
\text { en c3-c4 }\end{array}$ & $\begin{array}{l}\text { - Debilidad mus- } \\
\text { cular }(3 / 5) \text { y entu- } \\
\text { mecimiento en he- } \\
\text { micuerpo derecho } \\
\text { - Debilidad muscu- } \\
\text { lar }(1 / 5) \text { y entume- } \\
\text { cimiento en hemi- } \\
\text { cuerpo izquierdo }\end{array}$ & $\begin{array}{l}\text { - Pneumoencéfalo y } \\
\text { pneumorraquis en c6 } \\
\text { - Pneumoencéfalo y } \\
\text { pneumorraquis en c3 }\end{array}$ & (18) \\
\hline Newbold et al & 1987 & 24 & $M$ & $\begin{array}{l}\text { Trauma facial se- } \\
\text { cundario a acciden- } \\
\text { te de transito }\end{array}$ & $\begin{array}{l}\text { Paciente despierto } \\
\text { y sin alteración he- } \\
\text { modinámica. }\end{array}$ & $\begin{array}{l}\text { - Radiografía en re- } \\
\text { gión cervical lateral } \\
\text { mostró pneumorra- } \\
\text { quis. TAC de cráneo } \\
\text { mostró pneumoen- } \\
\text { céfalo y fractura fa- } \\
\text { cial extensa }\end{array}$ & (19) \\
\hline Oertel et al & 2005 & 19 & $M$ & $\begin{array}{l}\text { Secundario a episo- } \\
\text { dios de tos }\end{array}$ & $\begin{array}{l}\text { Tos, fiebre, náu- } \\
\text { seas y vómitos de } \\
3 \text { días más enfise- } \\
\text { ma subcutáneo }\end{array}$ & $\begin{array}{l}\text { TAC revela neumo- } \\
\text { mediastino, neu- } \\
\text { moretroperitoneo, } \\
\text { pneumoencéfalo y } \\
\text { pneumorraquis }\end{array}$ & (20) \\
\hline $\begin{array}{l}\text { Sinha \& Mant- } \\
\text { le }\end{array}$ & 2000 & 21 & $M$ & $\begin{array}{l}\text { Accidente de trán- } \\
\text { sito }\end{array}$ & $\begin{array}{l}\text { Alteración del es- } \\
\text { tado de conciencia } \\
\text { e hipotensión }\end{array}$ & $\begin{array}{l}\text { Rx cervical lateral } \\
\text { revela pneumorra- } \\
\text { quis, TAC de cráneo } \\
\text { muestra presencia } \\
\text { de pneumoencéfalo }\end{array}$ & (21) \\
\hline Jomir et al & 2009 & 27 & $M$ & $\begin{array}{l}\text { Úlcera sacra por } \\
\text { presión posterior a } \\
\text { paraplejía }\end{array}$ & $\begin{array}{l}\text { Cefalea ortostáti- } \\
\text { ca, náuseas y rigi- } \\
\text { dez nucal }\end{array}$ & $\begin{array}{l}\text { TAC de cráneo y } \\
\text { columna revela } \\
\text { pneumoencéfalo } \\
\text { más pneumorraquis } \\
\text { y fuga de LCR }\end{array}$ & (22) \\
\hline Coskun et al & 2009 & 49 & $M$ & $\begin{array}{l}\text { Trauma cerebral } \\
\text { por accidente de } \\
\text { transito }\end{array}$ & $\begin{array}{l}\text { Alteración de la } \\
\text { conciencia }\end{array}$ & $\begin{array}{l}\text { Pneumoe ncéfalo } \\
\text { que abarcaba región } \\
\text { supraselar, preponti- } \\
\text { na y cisterna perime- } \\
\text { sencefálica derecha }\end{array}$ & (23) \\
\hline
\end{tabular}




\begin{tabular}{|c|c|c|c|c|c|c|c|}
\hline Bozkurt et al & 2011 & 34 & $M$ & $\begin{array}{l}\text { Caída a } 15 \text { metros } \\
\text { de altura }\end{array}$ & Inconsciente & $\begin{array}{l}\text { TAC: Fractura bi- } \\
\text { temporal con pneu- } \\
\text { moencéfalo y TAC } \\
\text { espinal que revela } \\
\text { burbujas en región } \\
\text { torácica y lumbar }\end{array}$ & $(24)$ \\
\hline Amit $A$ et al & 2011 & 60 & $M$ & $\begin{array}{l}\text { Sepsis-intrabdomi- } \\
\text { nal }\end{array}$ & $\begin{array}{l}\text { Alteración de la } \\
\text { conciencia, pi- } \\
\text { rexia, dolor en } \\
\text { espalda, menin- } \\
\text { gismos }\end{array}$ & $\begin{array}{l}\text { TAC: Pneumorra- } \\
\text { quis, neumocranium } \\
\text { y neumoperitoneo }\end{array}$ & $(25)$ \\
\hline Kaya et al & 2010 & 7 & $M$ & $\begin{array}{l}\text { Accidente de trán- } \\
\text { sito }\end{array}$ & $\begin{array}{l}\text { Alteración de la } \\
\text { conciencia, hipo- } \\
\text { tensión y enfisema } \\
\text { en cuello }\end{array}$ & $\begin{array}{l}\text { Fractura en esfenoi- } \\
\text { des y parietal dere- } \\
\text { cho acompañado de } \\
\text { pneumoencéfalo y } \\
\text { pneumorraquis }\end{array}$ & $(26)$ \\
\hline Gill et al & 2011 & 18 & $M$ & $\begin{array}{l}\text { Accidente de trán- } \\
\text { sito }\end{array}$ & $\begin{array}{l}\text { Sangrado por na- } \\
\text { riz y oídos y altera- } \\
\text { ción en conciencia }\end{array}$ & $\begin{array}{l}\text { TAC: Edema ce- } \\
\text { rebral difuso con } \\
\text { pneumoencéfalo en } \\
\text { cisternas preponti- } \\
\text { nas y pneumorraquis } \\
\text { en } \mathrm{C} 6-\mathrm{C} 7\end{array}$ & $(27)$ \\
\hline Derner et al & 2011 & 41 & $M$ & $\begin{array}{l}\text { Traumatismo toráci- } \\
\text { co cerrado }\end{array}$ & $\begin{array}{l}\text { Parálisis en ex- } \\
\text { tremidad superior } \\
\text { derecha }\end{array}$ & $\begin{array}{l}\text { TAC muestra neu- } \\
\text { momediastino, } \\
\text { pneumoencéfalo } \\
\text { frontal y pneumo- } \\
\text { rraquis en transición } \\
\text { cervico-torácica }\end{array}$ & $(28)$ \\
\hline Wosko et al & 2011 & 24 & $M$ & $\begin{array}{l}\text { Traumatismo múl- } \\
\text { tiple por accidente } \\
\text { con laceración de } \\
\text { cordón espinal }\end{array}$ & - & $\begin{array}{l}\text { TAC revela neumo- } \\
\text { mediastino, pneu- } \\
\text { moencéfalo y pneu- } \\
\text { morraquis }\end{array}$ & $(29)$ \\
\hline Autores & Año & Edad & Género & $\begin{array}{l}\text { Mecanismo rela- } \\
\text { cionado }\end{array}$ & Síntomas & $\begin{array}{l}\text { Hallazgos por ima- } \\
\text { gen }\end{array}$ & Referencia \\
\hline $\begin{array}{l}\text { lacoangeli et } \\
\text { al }\end{array}$ & 2013 & 52 & $\mathrm{~F}$ & $\begin{array}{l}\text { Complicación por } \\
\text { cáncer de Colón }\end{array}$ & $\begin{array}{l}\text { Alteración neuro- } \\
\text { lógica }\end{array}$ & $\begin{array}{l}\text { TAC con pneumoen- } \\
\text { céfalo bifrontal }\end{array}$ & $(30)$ \\
\hline Germino et al & 2013 & 58 & $M$ & $\begin{array}{l}\text { Levantamiento de } \\
\text { pesas }\end{array}$ & $\begin{array}{l}\text { Dolor en cuello, } \\
\text { hombro y pares- } \\
\text { tesias en dedo y } \\
\text { manos }\end{array}$ & $\begin{array}{l}\text { TAC con hiperneu- } \\
\text { matización en re- } \\
\text { gión occipital, clivus } \\
\text { y C1-C2 }\end{array}$ & (31) \\
\hline $\begin{array}{l}\text { Karavelioglu } \\
\text { et al }\end{array}$ & 2014 & 56 & $M$ & $\begin{array}{l}\text { Posterior a laminec- } \\
\text { tomía con disec- } \\
\text { tomía }\end{array}$ & $\begin{array}{l}\text { Cefalea, náuseas } \\
\text { y mareos }\end{array}$ & $\begin{array}{l}\text { Pneumoencéfalo en } \\
\text { región supraselar y } \\
\text { cisterna basal con } \\
\text { pneumorraquis en } \\
\text { L4 }\end{array}$ & $(5)$ \\
\hline $\begin{array}{l}\text { Ergenoglu et } \\
\text { al }\end{array}$ & 2014 & 37 & $M$ & $\begin{array}{l}\text { Inyección epidural } \\
\text { de metilpredniso- } \\
\text { lona }\end{array}$ & $\begin{array}{l}\text { Dolor torácico y } \\
\text { cefalea }\end{array}$ & $\begin{array}{l}\text { Aire en ventrículo } \\
\text { lateral izquierdo más } \\
\text { pneumorraquis en } \\
\text { L2 }\end{array}$ & (32) \\
\hline Akyuz et al & 2016 & 62 & $F$ & $\begin{array}{l}\text { Posterior a laminec- } \\
\text { tomía L5-S1 }\end{array}$ & Cefalea más fiebre & $\begin{array}{l}\text { Pneumoencéfalo, } \\
\text { pneumorraquis en } \\
\text { región cervical y } \\
\text { lumbar }\end{array}$ & (33) \\
\hline
\end{tabular}




\begin{tabular}{|c|c|c|c|c|c|c|c|}
\hline Khalili et al & 2016 & 30 & $M$ & $\begin{array}{l}\text { Accidente de trán- } \\
\text { sito }\end{array}$ & $\begin{array}{l}\text { Deterioro neuroló- } \\
\text { gico y fuga de LCR }\end{array}$ & $\begin{array}{l}\text { Pneumoencéfalo } \\
\text { masivo a tensión con } \\
\text { signo de Monte Funji }\end{array}$ & (34) \\
\hline $\begin{array}{l}\text { Gun-Sang } \\
\text { Lee et al }\end{array}$ & 2016 & 47 & $F$ & $\begin{array}{l}\text { Posterior a cirugía } \\
\text { torácica }\end{array}$ & $\begin{array}{l}\text { Cefalea intensa } \\
\text { asociado a náu- } \\
\text { seas y vómitos }\end{array}$ & $\begin{array}{l}\text { Presencia de aire en } \\
\text { ventrículo y espacio } \\
\text { subaracnoideo, con } \\
\text { pneumorraquis en } \\
\text { T2 }\end{array}$ & (35) \\
\hline Kieser et al & 2017 & 59 & M & Posterior a cirugía & $\begin{array}{l}\text { Cefalea asociado } \\
\text { a disartria y con- } \\
\text { fusión }\end{array}$ & $\begin{array}{l}\text { Pneumoencéfalo su- } \\
\text { bural, subaracnoideo } \\
\text { y pneumorraquis }\end{array}$ & (36) \\
\hline Quintana et al & 2018 & 24 & $M$ & $\begin{array}{l}\text { Herida punzante en } \\
\text { cuello, brazo y re- } \\
\text { gión lumbar }\end{array}$ & $\begin{array}{l}\text { Cefalea con irra- } \\
\text { diación a región } \\
\text { cervical que em- } \\
\text { peora con la bipe- } \\
\text { destación }\end{array}$ & $\begin{array}{l}\text { Pneumoencéfalo y } \\
\text { pneumorraquis con } \\
\text { fistula a nivel de L4- } \\
\text { L5 }\end{array}$ & $\begin{array}{l}\text { Presente ar- } \\
\text { tículo }\end{array}$ \\
\hline
\end{tabular}

\section{Conclusiones}

Nuestro caso evidencia la importancia de hacer búsqueda imagenológica a ni- vel craneal de pneumoencéfalo posterior a lesiones raquídeas. El pneumoencéfalo asociado a pneumoraquis puede ser manejado de manera conservadora con resultados satisfactorios

Recibido: 4 de septiembre de 2018 Aceptado: 10 de octubre de 2018

\section{Referencias}

1. Andarcia-Bañuelos C, Cortés-García P, Herrera-Pérez MU, Deniz-Rodríguez B. Neumoencéfalo: Una inusual complicación de la artrodesis lumbar. Caso clínico y revision de la literatura. Rev Esp Cir Ortop Traumatol. 2015; 59(4): 222-6.

2. Rahamimov N, Mulla H, Freiman S. Cerebrospinal fluid leakage and pneumocephalus secondary to spine stab wounds. J Orthop Traumatol. 2010; 11(1):57-9.

3. Yun JH, Kim YJ, Yoo DS, Ko JH. Diffuse pneumocephalus: A rare complication of spinal surgery. J Korean Neurosurg Soc. 2010; 48(3): 288-90.

4. Padilla-Zambrano HS, Amaya-Quintero J, Yancarlos R, Moscote-Salazar LR, Calderón-Miranda WG, Mo-Carrascal J, et al. Postraumatic pneumorrhachis: report of three cases and classification proposal. Rom Neurosurg. 2017; XXXI(3): 3-8.

5. Karavelioglu E, Eser O, Haktanir A. Pneumocephalus and Pneumorrhachis after Spinal Surgery: Case Report and Review of the Literature. Neurol Med Chir (Tokyo) [Internet]. 2014;54(5):405-7. Available from: http://jlc.jst.go.jp/DN/JST.JSTAGE/nmc/cr2013-0118?lang=en\&fro $\mathrm{m}=$ CrossRef\&type $=$ abstract

6. Kankane V, Jaiswal G, Gupta T. Posttraumatic delayed tension pneumocephalus: Rare case with review of literature. Asian J Neurosurg 2016; 11(4): 343.

7. Eltorai IM, Montroy RE, Kaplan SL, Ho WH. Pneumocephalus secondary to cerebrospinal fluid leak associated with a lumbar pressure ulcer in a man with paraplegia. J Spinal Cord Med. 2003; 26(3): 262-9.

8. Schirmer CM, Heilman CB, Bhardwaj A. Pneumocephalus: Case illustrations and review. Neurocrit Care. 2010; 13(1): 152-8.

9. Kozikowski GP, Cohen SP. Lumbar puncture associated with pneumocephalus: Report of a case. Anesth Analg. 2004;98(2):524-6, table of contents.

10. DelGaudio JM, Ingley AP. Treatment of pneumocephalus after endoscopic sinus and microscopic skull base surgery. Am J Otolaryngol - Head Neck Med Surg. 2010; 31(4): 226-30.

11. Mirza S, Saeed SR, Ramsden RT. Extensive Tension Pneumocephalus Complicating Continuous Lumbar CSF Drainage for the Management of CSF Rhinorrhoea. ORL. 2003; 65(4): 215-8.

12. Gauthé R, Latrobe C, Damade C, Foulongne E, Roussignol X, Ould-Slimane M. Symptomatic compressive pneumocephalus following lumbar decompression surgery. Orthop Traumatol Surg Res. 2016; 102(2): 251-3.

13. Mirza S, Saeed SR, Ramsden RT. Extensive tension pneumocephalus complicating continuous lumbar CSF drainage for the management of CSF rhinorrhoea. Orl. 2003; 65(4): 215-8.

14. Mihaylova H, Fakih H. Cherubism - A case report. Rentgenol i Radiol. 2013; 52(3): 203-8.

15. Padilla-Zambrano HS, Amaya-Quintero J, Yancarlos R-V, Moscote-Salazar LR, Calderon-Miranda WG, Mo-Carrascal J, et al. Postraumatic pneumorrhachis: report of three cases and classification proposal. Rom Neurosurg. 2017; 31(3): 3-8.

16. Schömig B, Seliger C, Schulte-Mattler, W Angstwurm K, Fuchs K, Bogdahn U, Schlachetzki F. Clinical Reasoning: Pneumocephalus and pneumorrhachis in a 67-year-old man. Neurology. 2016; 86(21): 218-21.

17. Hsieh X, Hsieh S, Lu C, Wu Z, Ju D, Huh B, et al. A rare case of pneumocephalus and pneumorrhachis after epidural anesthesia. Acta Anaesthesiol Taiwan. 2015; 53(1): 47-9.

18. Kara H, Akinci M, Degirmenci S, Bayir A, Ak A. Traumatic pneumorrhachis: 2 cases and review of the literature. Am J Emerg Med. 2015; 33(6): 861 e1-3. 
19. Newbold G, David M, Vogler B. Traumatic Pneumorrhachis. AJR Am J Roentgeno. 1987; 148(3): 615-6.

20. Oertel MF, Korinth MC, Reinges MHT, Gilsbach JM. Pneumorrhachis of the entire spinal canal. J Neurol Neurosurg Psychiatry. 2005; 76(7): 1036.

21. Sinha PA, Mantle M. Cervical pneumorrhachis. Clin Radiol. 2000; 55(7): 569-70.

22. Jomir L, Fuentes S, Gélis A, Labauge P. Pneumorrhachis and pneumocephalus due to a sacral pressure sore after paraplegia. Neurorehabil Neural Repair. 2009; 23(7): 745-6.

23. Coskun S, Sahin M, Cobanoglu M, Kilicaslan I. Entire pneumorrhachis due to isolated head trauma. Am J Emerg Med. $2009 ; 27(7): 3-6$.

24. Bozkurt G, Turk CC, Ayhan S, Akbay A, Palaoglu S. Cervical pneumorrhachis caused by impact loading forces after skull base fracture: case report and review of the literature. Cent Eur Neurosurg. 2011; 72(4): 215-8.

25. Amit A, Toll EC, Siddique S, Nelson RJ. Pneumorrhachis with pneumocranium: An unusual complication of intra-abdominal sepsis. Br J Neurosurg. 2011; 25(1): 111-2.

26. Kaya U, Akay H, Arslan ED, Günaydn M, Büyükcam F, Tez M. Traumatic pneumorrhachis in a Child: Case report. Pediatr Emerg Care. 2010; 26(11): 852-3.

27. Gill M, Sreenivas M, Beniwal RS. Post-traumatic cervical pneumorrhachis - A rare entity. Br J Neurosurg. 2011; 25(1): 134-5.

28. Derner M, Drugová B, Hořejší L, Skvára D, Druga R. Massive pneumorrhachis, pneumocephalus and pneumoopticus following thoracic trauma and avulsion of the brachial plexus: case report and review of the literature. 2011. 112(1): 56-66.

29. Wośko J, Dabrowski W, Zadora P, Fijalkowska A, Grzycka-Kowalczyk L. Pneumocephalus and pneumorrhachis after chest wall injury. Anestezjol Intens Ter. 2011; 43(1): 40-4.

30. lacoangeli M, Di Rienzo A, Fianchini A, Marmorale C, Alvaro L, Nocchi N, et al. Acute tension pneumocephalus secondary to whole spine pneumorrhachis as an unusual presentation of a colon cancer complicated by a transsacral cerebrospinal fluid leak. J Clin Neurosci. 2013; 20(3): 469-71.

31. Germino JC, Medverd JR, Nguyen VT, Favinger JL, Marder CP. Craniocervical hyperpneumatization with concurrent pneumorrhachis, pneumomediastinum, and subcutaneous emphysema in a weightlifter. Spine J [Internet]. 2013;13(10):e47-53. Available from: http://dx.doi. org/10.1016/j.spinee.2013.06.033

32. Ergenoglu P, Bali C, Akin S, Ozyilkan N, Aribogan A. Pneumorrhachis and Pneumocephalus with Severe Chest Pain Symptom: A Rare Complication of Epidural Steroid Injection Spontaneous Air Reduction of Vertebra Plana with Kummell 's Disease During Vertebroplasty: Subsequent Experience with an Intentional Tri. Pain Med. 2014; 15(7): 1239-40.

33. Akyüz O, Gökpınar D, Aydın E, Aydın S, Duymuş M, Çığşar G, et al. Pneumocephalus and pneumorrhachis after spinal surgery. Polish J Radiol [Internet]. 2016;81:34-5. Available from: https://www.scopus.com/inward/record.uri?eid=2-s2.0-84956894864\&doi=10.12659\% 2FPJR.895570\&partnerID=40\&md5=9716cca490d12afda5960146d63cd6e 7

34. Khalili H, Niakan A, Ghaffarpasand F. Massive Pneumocephalus and Pneumorrhachis. Bull Emerg Trauma. 2016; 4(4): 248-9.

35. Lee G, Lee M, Kim W, Kim H, Kim J, Kim Y. Pneumocephalus and Pneumorrhachis due to a Subarachnoid Pleural Fistula That Developed after Thoracic Spine Surgery. 2016; 13(3): 164-6.

36. Kieser DC, Cawley DT, Tavolaro C, Cloche T, Roscop C, Boissiere L, et al. Erratum to: Delayed post-operative tension pneumocephalus and pneumorrhachis (European Spine Journal, (2018), 27, 1, (231-235), 10.1007/s00586-017-5268-3). Eur Spine J. $2018 ; 27(1)$ : 238.

\section{Correspondencia a:}

Dr. Luis Rafael Moscote-Salazar

mineurocirujano@aol.com 